REVISTA DE DERECHO UNED, NÚM. 9, 2011

\title{
LA RESPONSABILIDAD CIVIL SUBSIDIARIA $E X$ DELICTO DERIVADA DEL ART. 121 DEL CÓDIGO PENAL Y LA RESPONSABILIDAD PATRIMONIAL DE LAS ADMINISTRACIONES PÚBLICAS. BREVE APROXIMACIÓN JURISPRUDENCIAL
}

\author{
Roger CÀMARA MAS \\ Técnico de Administración General. Postgrado Derecho de la \\ Ordenación Territorial y Urbanística (IDEC. UPF). \\ Experto Universitario en Función Pública (UNED)
}

Resumen: El presente trabajo estudia las relaciones entre la responsabilidad civil ex delicto derivada del art. 121 del Código Penal y la responsabilidad patrimonial de las administraciones públicas especialmente en su vertiente procesal. Para ello, se parte del análisis de la jurisprudencia dictada por los tribunales del orden jurisdiccional civil, penal y contencioso-administrativo. La interpretación efectuada por las salas segunda y tercera del Tribunal Supremo ha contribuido a configurar ambas acciones como plenamente autónomas entre sí, admitiendo la posibilidad de su ejercicio simultáneo o sucesivo, doctrina que se aparta de la propia conceptualización de la acción civil ex delicto realizada por la sala primera del mismo tribunal.

Palabras clave: Responsabilidad civil derivada del delito; responsabilidad patrimonial de las administraciones públicas; responsabilidad de autoridades y funcionarios públicos; acción civil.

Abstract: This article studies the relations between the civil responsibility ex delicto derivative from the article 121 of Penal Code and the patrimonial responsibility of the public administrations specifically in the procedural order. This study splits the analysis of the jurisprudence dictated by the courts of the civil, penal and conten- 
tious-administrative jurisdiction. The interpretation effected by the second and third chamber of the Supreme Court has helped for both actions to be fully autonomous, admitting the possibility of his simultaneous or successive exercise, doctrine that is separated of the own conceptualization of the civil action ex delicto realized by the first chamber of the same court.

Key words: Civil responsibility derived from the crime; patrimonial responsibility of the public administrations; responsibility of authorities and government employees; civil action.

Sumario: I. Introducción.-II. La tramitación simultánea de ambos procedimientos.-III. La tramitación sucesiva de ambos procedimientos.-III.1. Resolución penal previa condenatoria.-III.2. Resolución penal previa absolutoria.-III.3. Finalización previa del procedimiento administrativo o contencioso-administrativo estimando o desestimado la reclamación de responsabilidad patrimonial.-IV. Conclusiones.

\section{INTRODUCCIÓN}

El artículo 121 de la Ley Orgánica 10/1995, de 23 de noviembre, del Código Penal dispone que el Estado, la Comunidad Autónoma, la provincia, la isla, el municipio y demás entes públicos, según los casos, responden subsidiariamente de los daños causados por los penalmente responsables de los delitos dolosos o culposos, cuando éstos sean autoridad, agentes y contratados de la misma o funcionarios públicos en el ejercicio de sus cargos o funciones siempre que la lesión sea consecuencia directa del funcionamiento de los servicios públicos que les estuvieren confiados, sin perjuicio -añade el precepto- de la responsabilidad patrimonial derivada del funcionamiento normal o anormal de dichos servicios exigible conforme a las normas de procedimiento administrativo ${ }^{1}$. Al establecer esta previsión, parece que el legislador haya señalado la compatibilidad entre el ejercicio de la acción civil ex delicto y la acción de reclamación de responsabilidad patrimonial: la víctima podrá exigir la responsabilidad civil ex delicto de los entes públicos pero también podrá plantear en vía adminis-

${ }^{1}$ Debemos señalar que el estado y demás entes públicos pueden ser también declarados responsables civiles con carácter subsidiario por la comisión de ilícitos penales al amparo de otros preceptos del Código Penal como el art. 120.3, el 120.4 o el 120.1 . 
trativa la oportuna reclamación de responsabilidad patrimonial con el límite de la duplicidad indemnizatoria.

Sobre esta cuestión, la sentencia de la Audiencia Provincial de Tenerife $\mathrm{n}^{\circ} 619 / 2008$, de 30 de setiembre (JUR 2009\49169) destaca que «si bien es cierto que el artículo 121 del C. Penal establece que no puede darse una duplicidad indemnizatoria, no hay que olvidar en primer lugar que es compatible la responsabilidad patrimonial de la administración con la derivada de delito o falta, ya que una deriva precisamente de la responsabilidad penal, y la de la administración dimana del hecho de un anormal funcionamiento de los servicios públicos».

La sentencia del Tribunal Supremo de 5 de noviembre de 1997, de la Sala de lo Contencioso-administrativo (RJ 1997 8298), resulta de gran trascendencia y se pronuncia de forma que no deja lugar a dudas sobre la compatibilidad de la responsabilidad patrimonial de las administraciones públicas con la responsabilidad civil ex delicto. Reproducimos el fundamento jurídico séptimo de la citada sentencia que desestima las alegaciones efectuadas por la Abogacía del Estado que sostienen que no es posible que de un mismo hecho se devenguen dos responsabilidades distintas, una administrativa y una penal, puesto que se cobraría dos veces por el mismo suceso: «La proyección de los anteriores criterios jurisprudenciales a la cuestión examinada, permite sentar las siguientes consecuencias:

1. $\left.{ }^{a}\right)$ El fundamento de la pretensión que discurre por el procedimiento administrativo no se anuda a ningún delito (como reconoce la STS 2 noviembre 1991 [RJ 1991\8868]) sino a una responsabilidad objetiva de la Administración prevista, en el caso examinado, en el artículo 40 LRJAE, pues lo único que constituye el objeto específico de este proceso es decidir si la Administración debe responder objetivamente como prestadora de un servicio público.

2. $\left.{ }^{a}\right)$ En consecuencia, hay que partir de los puntos a estudiar en materia de responsabilidad administrativa, teniendo presente el derecho de los particulares a ser indemnizados por las lesiones que sufran a consecuencia del funcionamiento normal o anormal de los servicios públicos, salvo los casos de fuerza mayor (artículos 106.2 de la Constitución Española y 40.1 LRJAE) dando a la expresión de servicio público un sentido amplio como toda actuación, gestión o actividad propias de la función administrativa, incluso por la omisión o pasividad cuando la Administración tiene el concreto deber de obrar o comportarse de modo determinado (SSTS 5 junio 1989 [RJ 1989\4338], 17 noviembre 1990 [RJ 1990\9172] y 22 noviembre 1991 [RJ 1991\8844]). 
3. ${ }^{a}$ La diferencia entre el proceso penal y administrativo, permite destacar los siguientes puntos:

A) El procedimiento seguido por el Juzgado de Instrucción de Burgos tenía una finalidad concreta y determinada, es decir, la averiguación de la existencia de delito por acción u omisión, sin perjuicio de las responsabilidades civiles que en su caso pudieran declararse, actividad instructora completamente diferente del procedimiento netamente administrativo que se está siguiendo en este caso.

B) Las facultades que competen a la Administración Pública definen por sí misma la existencia o no de lesión indemnizable, de conformidad con los principios que inspiran el sistema vigente de la responsabilidad patrimonial de la Administración.

C) Incumbía a la Administración la obligación de resolver las peticiones que por los particulares se le dirijan (artículo 39 de la Ley de Régimen Jurídico).

D) Existen diferencias conceptuales y de regulación legal existentes entre la responsabilidad civil subsidiaria del Estado y la responsabilidad patrimonial de la Administración, ya que la primera de las responsabilidades citadas se fundamenta en el principio de que toda persona responsable criminalmente de un delito o falta lo es también civilmente, siéndolo subsidiariamente el Estado, de acuerdo con la jurisprudencia existente, lo que significa que, dictada sentencia declarando culpable a cualquier funcionario del Departamento, en razón de las actividades públicas que tenga encomendadas por su cargo, puede decretarse la responsabilidad civil subsidiaria del Estado, ante la posible insolvencia del condenado.

E) A diferencia de la anterior, la responsabilidad patrimonial de la Administración es esencialmente de carácter objetivo, lo que presupone que se genera sin necesidad de culpa o negligencia del obligado a reparar el daño (en este caso el Estado). La declaración de responsabilidad patrimonial se obtiene en la vía administrativa, mediante la tramitación del oportuno expediente, sin precisar intervención judicial alguna y se fundamenta en la existencia de una lesión (en bienes o derechos) para el particular perjudicado, que éste no deba soportar legítimamente, como consecuencia del funcionamiento normal o anormal de los servicios públicos (artículos 40 de la Ley de Régimen Jurídico, 106 de la Constitución Española y hoy artículos 139 y siguientes de la Ley 30/1992 [RCL 1992\2512, 2775 y RCL 1993\246]).

Los razonamientos anteriormente expuestos conducen a la desestimación del tercero de los motivos de casación invocados por el Abogado del Estado». 
En el mismo sentido, la sentencia del Tribunal Supremo $\mathrm{n}^{\circ}$ 237/1996, de 11 de marzo, Sala de lo Penal (RJ 1996\1906), dispone que la «responsabilidad subsidiaria del estado es ajena al derecho que el art. 106.2 de la Constitución atorga a los particulares para ser indemnizados por el mal funcionamiento de los servicios públicos en general, como también lo es respecto del perjuicio sufrido por el anormal funcionamiento de la Administración de justicia o por error judicial».

La compatibilidad de ambas figuras encuentra el fundamento precisamente en su distinta naturaleza jurídica. La sentencia del Tribunal Supremo, sala de lo criminal, de 23 de octubre de 1984 (RJ 1984\5061), dice que «una cosa es la responsabilidad civil subsidiaria que al Estado puede alcanzar por los actos delictivos cometidos por quienes se hallen respecto a él en situación de dependencia, la que es exigible en un proceso penal, y otra cosa completamente distinta la responsabilidad patrimonial en la que el Estado puede haber incurrido a causa del funcionamiento normal o anormal de los servicios públicos la que ha de exigirse mediante el ejercicio de la oportuna acción en el procedimiento correspondiente que no es el penal»².

Precisamente al tener distinta naturaleza jurídica, no se puede exigir en vía penal la responsabilidad patrimonial de la administración. Así lo destaca el auto $n^{\circ} 58 / 2000$, de 6 de octubre, del Tribunal Superior de Justicia de la Comunidad Valenciana (ARP 2000\3344) cuando dispone que "Acerca de la alegación formulada en el acto de la vista por la letrada del recurrente don Julio P. C., consistente sustancialmente en que la responsabilidad del Estado por el normal o anormal funcionamiento de los servicios públicos recogida en el artículo 106 de la Constitución Española debería dilucidarse dentro del propio proceso penal para evitar dilaciones indebidas y dar la debida tutela judicial efectiva, ya que esta responsabilidad no viene atribuida en la Constitución a un orden jurisdiccional concreto, es de señalar que no es posible su estimación.

En efecto, se ha de precisar que la responsabilidad civil subsidiaria de terceros, incluso de la Administración pública, y la responsabilidad patrimonial de las Administraciones públicas, son institutos distintos y no obedecen a las mismas reglas jurídicas. La primera de ellas, a la que se contrae fundamentalmente este recurso, viene derivada de lo establecido en el artículo 121 del Código Penal y requiere de una serie de re-

2 Puede consultarse también la STS de 17 de julio de 1992 (RJ 1992\6475); STSJ Madrid de 19 de julio de 2002 (RJCA 2003\559); SAN de 5 de febrero de 2010 (RJCA $2010 \backslash 161$ ), SAN de 5 de febrero (RJCA 2010\49937) y 15 de febrero de 2010 (RJCA 2010 232), las tres últimas referentes al mismo supuesto. 
quisitos de vinculación del penalmente responsable respecto de la Administración pública correspondiente y de su actuación en el ejercicio de sus funciones propias y de cuya concurrencia no se deriva la condición de legitimado pasivo en el proceso penal correspondiente, en este caso del Estado; esta responsabilidad requiere de un juicio de culpabilidad, además de los requisitos específicos contenidos en estas normas. La segunda de éstas es la responsabilidad de la Administración pública por el funcionamiento de los servicios públicos, que no exige un juicio de culpabilidad sino de nexo de causalidad, regulada por los citados artículos 106 de la Constitución Española y 139 y siguientes de la Ley de Régimen Jurídico de las Administraciones Públicas y del Procedimiento Administrativo Común, cuya exigencia se ha de ha producir por vía administrativa y, en caso de denegación, mediante el correspondiente recurso contencioso-administrativo, de conformidad con lo establecido en los artículos 142.6 de la dicha Ley de Régimen Jurídico de las Administraciones Públicas y del Procedimiento Administrativo Común y 2.e) de la Ley 29/1998 (RCL 1998, 1741) reguladora de la Jurisdicción Contencioso-Administrativa, que prohíbe expresamente que las Administraciones públicas sean demandadas por este motivo ante los órdenes jurisdiccionales civil o social.

\section{OCTAVO}

Ambas responsabilidades responden a figuras distintas que pueden ser utilizadas de forma sucesiva o simultánea, si bien el propio artículo 121 del Código Penal no admite la duplicidad de indemnizaciones por los mismos hechos; lo que no cabe, a tenor de estos preceptos y en especial del último señalado, es que el orden jurisdiccional penal resuelva sobre el instituto de la responsabilidad patrimonial de las Administraciones públicas, ya que su ámbito competencial sólo alcanza al instituto de las responsabilidad civil subsidiaria de éstas y en los limitados términos que para ello establece el dicho precepto del Código Penal; esta cuestión acerca de la extensión de los distintos órdenes jurisdiccionales en la materia de la responsabilidad de las Administraciones públicas, por una u otra vía, civil o patrimonial, ha sido objeto de debate y controversia en la doctrina jurisprudencial y la científica a lo largo de un dilatado período de tiempo y la decisión del legislador, que sólo cabe acatar y cumplir, por la vía de los citados preceptos de la Ley de Régimen Jurídico de las Administraciones Públicas y del Procedimiento Administrativo Común y Ley reguladora de la Jurisdicción Contencioso-Administrativa, ha sido la que resulta de la exposición hecha; es decir, que la responsabilidad patrimonial de las Administraciones públicas tiene carácter administrativo y ha de ser enjuiciada por el orden contencioso- 
administrativo y, tan sólo si se dan los requisitos establecidos en el Código Penal, cabe alternativamente que la responsabilidad civil con carácter subsidiario de éstas sea enjuiciada por el orden penal; en consecuencia, en ningún caso cabe plantear en el proceso penal la responsabilidad de las Administraciones públicas, según las reglas de la responsabilidad patrimonial de las mismas».

En el caso que no concurran los presupuestos establecidos en el art. 121 del Código Penal para la exigencia de la responsabilidad civil ex delicto de las administraciones públicas, en ningún caso éstas podrán ser condenadas como responsables civiles en vía penal, sin perjuicio que se ejerza en vía administrativa la oportuna acción de responsabilidad patrimonial ${ }^{3}$. La sentencia $n^{\circ}$ 803/1999, de 24 de mayo, del Tribunal Supremo, sala de lo penal (RJ 1999\3383) así lo señala en los siguientes términos: " $Y$ el principio de igualdad y de no discriminación sólo es quebrantado, por obra de la sentencia de un Tribunal, cuando dos casos sustancialmente idénticos son resueltos de distinta forma sin que la diversidad de la respuesta sea razonablemente motivada, siendo evidente que el caso en que tiene su origen este recurso se diferencia del que trae a colación el recurrente en un aspecto de todo punto esencial: que en la Sentencia recurrida no ha sido condenado, como responsable de delito o falta, ninguna autoridad o funcionario dependiente de la Administración Pública, por lo que falta un presupuesto fáctico imprescindible para que pueda ser aplicado el art. 22 CP y declarada la responsabilidad civil subsidiaria del Estado. Si el recurrente entiende que tiene derecho a ser indemnizado por el Estado, en razón del rapto, violación y asesinato de su hija, a causa de lo que estima mal funcionamiento de los servicios públicos de seguridad, debe utilizar el procedimiento establecido en el art. 142 de la Ley 30/1992, de Régimen Jurídico de las Administraciones Públicas y del Procedimiento Administrativo Común, pero no plantear su pretensión en un proceso penal donde ninguna acción de esta naturaleza ha sido ejercitada contra servidor alguno de la Administración Pública. Todo lo

${ }^{3}$ Son cuatro los requisitos de carácter sustantivo que exige el art. 121 del Código Penal:

a) la comisión de un delito doloso o culposo.

b) los sujetos activos de la infracción penal han de tener la condición de autoridades, funcionarios públicos, agentes o contratados de los entes públicos.

c) Los sujetos activos se han de encontrar en el ejercicio de sus cargos o funciones públicas.

d) La lesión producida ha de ser consecuencia directa de los servicios públicos que les estuvieren confiados. 
cual no puede llevar sino al más terminante rechazo del segundo motivo del recurso" ${ }^{4}$.

En resumen, el propio precepto y la jurisprudencia dictada en su aplicación reconocen el posible ejercicio de las dos acciones por los mismos hechos, ya sea de forma simultánea o sucesiva. Siguiendo la brillante exposición de Edmundo $\mathrm{Bal}^{5}$ podemos establecer las siguientes combinaciones en el ejercicio de ambas acciones:

a) la tramitación simultánea de los dos procedimientos.

b) la tramitación sucesiva de ambos procedimientos, distinguiendo si hay o no sentencia penal condenatoria y resolución administrativa estimatoria o desestimatoria.

\section{LA TRAMITACIÓN SIMULTÁNEA DE AMBOS PROCEDIMIENTOS}

De conformidad con el art. 146.2 de la Ley 30/1992, de 26 de noviembre, se puede tramitar de forma simultánea un proceso penal para la exigencia de responsabilidad penal al personal al servicio de las administraciones públicas con ejercicio simultáneo de la acción civil derivada del delito y un procedimiento administrativo de exigencia de responsabilidad patrimonial ${ }^{6}$. La única salvedad que dispone el precepto es que la determinación de los hechos en el orden penal no sea necesaria para la fijación de la responsabilidad patrimonial. Esta salvedad, que aparece en el precepto como una excepción, en nuestra opinión debe ser la regla general, puesto que en casi todos los casos la determinación penal de los hechos será un elemento necesario e imprescindible a tener en cuenta en el procedimiento administrativo ${ }^{7}$. Además, y desde el punto de vista de la vícti-

${ }^{4}$ En el mismo sentido se pronuncia la sentencia de la Audiencia Provincial de Asturias $\mathrm{n}^{\circ}$ 298/2001, de 24 de octubre (JUR 2002\34367).

5 BAL FRANCÉs, Edmundo. «La responsabilidad civil subsidiaria y la responsabilidad administrativa por funcionamiento de servicios públicos. ¿Dualidad de acciones?». Centro de estudios jurídicos, 2004, pág. 735-764.

${ }^{6}$ El art. 146.2 de la Ley 30/1992, de 26 de noviembre, en la nueva redacción del precepto efectuada por la Ley 4/1999, de 13 de enero, dispone que «La exigencia de responsabilidad penal del personal al servicio de las Administraciones públicas no suspenderá los procedimientos de reconocimiento de responsabilidad patrimonial que se instruyan, salvo que la determinación de los hechos en el orden jurisdiccional penal sea necesaria para la fijación de la responsabilidad patrimonial».

${ }^{7}$ La jurisprudencia de los tribunales de lo contencioso-administrativo a favor de la interrupción del plazo para la interposición de la reclamación de responsabilidad patrimonial cuando se ejerce la acción penal y no se renuncia a la civil derivada del 
ma, el proceso penal a la práctica guarda mayores garantías que el procedimiento administrativo, en el que la administración se convierte en juez y parte a la vez, aunque se pueda acudir a los juzgados y tribunales de lo contencioso-administrativo para revisar la resolución adoptada por ésta. En este sentido, es lógico que se acuerde la suspensión del procedimiento administrativo a la espera de que el juez penal dicte sentencia estableciendo los hechos considerados probados.

No obstante, el Tribunal Supremo ha tenido ocasión de pronunciarse sobre esta cuestión y se decanta en consonancia de esta posible tramitación simultánea. Así, en sentencia de 18 de noviembre de 1996 de la Sala de lo Contencioso-Administrativo (RJ 1996\8063) afirma que «No puede prosperar el recurso de apelación interpuesto por el señor Abogado del estado contra la sentencia recurrida ya que no son aceptables las alegaciones que invoca en el mencionado recurso. Así y en primer lugar no existe infracción del artículo 114 de la Ley de Enjuiciamiento Criminal en relación con el artículo 10 de la Ley Orgánica del Poder Judicial (RCL 1985\1578, 2635 y ApNDL 8375). El hecho de que se haya promovido un juicio criminal en averiguación del delito que pudiera haberse cometido en el Centro Penitenciario de Detención de Hombres de Barcelona, la noche del 20 de septiembre de 1983, cuando como consecuencia de los golpes recibidos de otros internos falleció Francisco Javier G. F. -que se encontraba en prisión provisional- no es motivo suficiente para suspender o paralizar el recurso contencioso-administrativo seguido ante esta Jurisdicción, a fin de determinar la responsabilidad patrimonial que incumbe al Estado. Y ello es así porque se trata de hechos distintos. De un lado, la comisión de un presunto delito que da lugar a la indagación en el oportuno procedimiento penal. De otro, el funcionamiento normal o anormal de un servicio público que genera y configura la responsabilidad patrimonial, directa y objetiva, de la Administración. Esta responsabilidad a tenor de los artículos 121 de la Ley de Expropiación Forzosa (RCL 1954\1848 y NDL 12531) y 40 de la Ley de Régimen Jurídico de la Administración del Estado (RCL 19571058 y NDL 25852) se configura como una responsabilidad di-

delito en el proceso penal constituye un argumento que refuerza esta tesis. Entre otras, citamos la STS de 5 de noviembre de 1997 (RJ 1997\8298), STS de 12 de junio de 2008 (RJ 2008\6375), STS de 22 de abril de 2009 (RJ 2009\122), SAN de 15 de julio de 2007 (JUR 2007 229174), STSJ Madrid 982/2004, de 11 de junio (RJ 2004\272123); STSJ Madrid 1262/2002, de 21 de noviembre (JUR 2003\169072), STSJ Navarra de 27 de abril de 2000 (RJCA 2000\1587); STSJ Castilla y León 2/2005, de 7 de enero (JUR 2005\33515); STSJ Castilla y León 121/2001, de 16 de marzo (JUR 2001\106231). 
recta, no como un simple sistema de cobertura de los daños causados por los actos ilícitos de funcionarios y agentes de los entes públicos. Por otra parte, se prescinde en ella del elemento tradicional de ilicitud o culpa para articularse como una responsabilidad puramente objetiva, en la que la Administración responde de toda lesión que los particulares sufran siempre que sea a consecuencia del funcionamiento normal o anormal de los servicios públicos. Es por ello una responsabilidad compatible con la responsabilidad criminal como dice el Tribunal " $a$ quo" invocando la Sentencia de este Tribunal de 13 marzo 1989 (RJ 1989\1986). Se trata, por lo tanto, en este caso, del ejercicio de una acción indemnizatoria con independencia y al margen del juicio criminal que pueda seguirse para depurar las responsabilidades exigibles a los acusados de la agresión al fallecido, juicio que se tramita mediante el sumario 12/1985 en el Juzgado de Instrucción núm. 13 de Barcelona» ${ }^{8}$. El distinto fundamento de ambas instituciones es de nuevo el argumento que utiliza el Alto Tribunal para justificar la tramitación simultánea de ambos procedimientos.

Esta cuestión, pero, no es pacífica puesto que hay jurisprudencia que se posiciona de forma inequívoca por la existencia en estos casos de una auténtica cuestión prejudicial sustantiva de carácter penal que en aplicación del art. 114 de la Ley de Enjuiciamiento Criminal y del art. 4.1 de la Ley 29/1998, de 13 de julio, reguladora de la Jurisdicción Contencioso-Administrativa motiva la suspensión del procedimiento administrativo o contencioso-administrativo hasta la resolución de ésta9 . Esta segunda línea jurisprudencial es la que a nuestro criterio parece más acertada por los motivos anteriormente señalados.

\section{LA TRAMITACIÓN SUCESIVA DE AMBOS PROCEDIMIENTOS}

En este caso, es imprescindible distinguir dos situaciones: una primera, en la que hay resolución penal previa y una segunda en la que hay resolución administrativa previa sobre los mismos hechos. De todos formas, debemos precisar que en la práctica procesal el segundo supuesto es poco habitual, aunque debe ser también objeto de análisis porque teóricamente es posible que tenga lugar.

8 STS de 2 de febrero de 1980 (RJ 1980\743); STS de 9 de junio de 1998 (RJ 1998\5172); SAN de 5 de febrero de 2010 (RJCA 2010 161); SAN de 5 de febrero (RJCA 2010 49937) y 15 de febrero de 2010 (RJCA 2010 232).

9 STS de 31 de octubre de 2007 (RJ 2007 8478); STS de 5 de noviembre de 1997 (RJ 1997 8298); STSJ Canarias 6/2002, de 9 de enero (RJCA 2002\1142). 


\section{III.1. Resolución penal previa condenatoria}

La existencia de resolución penal previa condenatoria no constituye ningún obstáculo para el ejercicio posterior de la acción de responsabilidad patrimonial en vía administrativa (o contencioso-administrativa) en relación a los mismos hechos. La jurisprudencia mayoritaria se pronuncia en esta línea como hemos tenido ocasión de ver en el inicio de la exposición. Las sentencias sobre el caso de la presa de Tous recaídas primero en vía penal y posteriormente en vía administrativa son significativas. Reproducimos parte de los argumentos contemplados en el fundamento jurídico tercero de la sentencia del Tribunal Supremo de 20 de octubre de 1997, Sala de lo Contencioso-Administrativo (RJ 1997 7254 , caso Tous):

"Así, ha declarado la jurisprudencia de este Tribunal (en Sentencias de 30 mayo 1983 [RJ 1983 2919], 15 junio, 13 julio, 18 julio y 4 y 12 di-

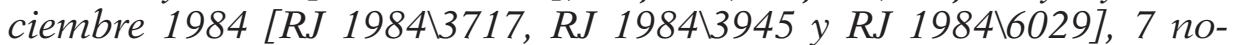
viembre 1985 [RJ 1985\5515] y 27 mayo 1994 [RJ 1994\4325], entre otras) los siguientes criterios de aplicación al caso examinado:

a) Fuera del caso previsto en el artículo 116.1 de la Ley de Enjuiciamiento Criminal (declaración de que no existió el hecho de que la responsabilidad civil hubiera podido nacer) las sentencias absolutorias de la jurisdicción penal no vedan a otros Tribunales para calificar el hecho como culposo o negligente en el ámbito civil y generador de la obligación de indemnizar, al amparo del artículo 1902 del Código Civil.

b) La Jurisdicción Penal no puede limitar ni condicionar la potestad específica de la jurisdicción contencioso-administrativa, pues una y otra obligación nacen de causas distintas: la primera, de naturaleza penal para determinar la responsabilidad punible de los autores, la segunda dimana del funcionamiento de los servicios públicos y es determinante para concretar la responsabilidad patrimonial o extracontractual de la Administración.

c) Esta Sala, en Auto de 16 marzo 1987 acordó la suspensión del recurso contencioso-administrativo hasta que se dictase sentencia penal, dimanante del sumario 56/1982, instruido por el Juzgado de Instrucción de Játiva, con fundamento en los artículos 114 de la Ley de Enjuiciamiento Criminal y 4.1 de la LJCA, lo que ha sucedido en la actualidad, habiendo reconocido el Auto de la Sección 2. ${ }^{a}$ de esta Sala de 3 septiembre 1993 que las reglas contenidas en el artículo 146.2 de la Ley 30/1992 (RCL 1992 2512, 2775 y RCL 1993\246) (no suspensión de los procedimientos de reconocimiento de responsabilidad patrimonial ante la exigencia de responsabilidad penal del personal al servicio de las 
Administraciones Públicas, salvo que la determinación de los hechos en el orden jurisdiccional penal sea necesario para la fijación de responsabilidad patrimonial) con arreglo a la disposición transitoria 2.1, no era de aplicación a los procedimientos iniciados antes de la entrada en vigor de la Ley, que se regirían por la normativa anterior.

d) Este criterio es coherente con las SSTS 10 y 31 enero, 12 marzo y 17 julio 1992 ( $R J$ 1992\615, RJ 1992\2242 y RJ 1992\6681) que reconocen la responsabilidad civil subsidiaria del Estado en el caso de intervención de miembros de las Fuerzas y Cuerpos de Seguridad del Estado, con independencia de la responsabilidad patrimonial que corresponde a la Administración Pública y que establece el artículo 106.2 de la Constitución Española como sistema unitario de responsabilidad objetiva directa de la Administración Pública por el funcionamiento de los servicios públicos, máxime cuando respetando los hechos probados de la sentencia penal precedente no se entra a decidir la relación entre la conducta del culpable y el servicio público, cuya responsabilidad, habrá de exigirse en este procedimiento, sin darse duplicidad de actuaciones ni indemnizatoria (como indica el artículo 121.1 del Código Penal-Ley Orgánica 10/1995, de 23 noviembre [RCL 1995\3170 y RCL 1996\777]-) (...)».

En consecuencia, una resolución penal previa condenatoria no impediría la apertura de un nuevo procedimiento en vía administrativa (o contencioso-administrativa) sobre los mismos hechos siempre y cuando se respeten dos límites: la prohibición de enriquecimiento injusto que establece el art. 121 del Código Penal ${ }^{10}$ y la determinación de los hechos declarados probados por la sentencia penal una vez adquiere firmeza ${ }^{11}$. Una interpretación literal del art. 121 del Código Penal nos llevaría a la misma conclusión al establecer la compatibilidad en el ejercicio de ambas acciones.

10 Sobre la plena aplicabilidad de este principio la jurisprudencia es unánime: SAN de 30 de junio de 2008 (JUR 2008/377096); STSJ Canarias n $^{\circ}$ 123/2008, de 31 de octubre (JUR 2009\49169); STSJ Cataluña n ${ }^{\circ}$ 204/2007, de 19 de marzo (JUR 2007 148949); SAN de 15 de julio de 2007 (JUR 2007 229174); STSJ Comunidad Valenciana $n^{\circ} 241 / 2003$, de 22 de febrero (RJCA 2004\2); STSJ Canarias $n^{\circ} 6 / 2002$, de 9 de enero (RJCA 2002\1142); STS de 12 de noviembre de 1998 (RJ 1998\9148); STS de 26 de septiembre de 1997 (RJ 1997\6366); STS de 20 de octubre de 1997 (RJ 1997 7254); STS de 6 de febrero de 1987 (RJ 1987 2749).

11 STS de 22 de abril de 2009 (RJ 2009\5122); STS de 23 de abril de 2008 (RJ 2008\2730); STSJ de la Comunidad Valenciana $n^{\circ}$ 235/2006, de 28 de febrero (JUR 2006 223867); SAN de 8 de junio de 2004 (JUR 2005\222611); STSJ de Castilla y León $n^{\circ}$ 606/2004, de 17 de diciembre (RJCA 2005\5); STS de 3 de abril de 2003 (RJ 2003\3669); SAN de 17 de septiembre de 2003 (RJCA 2004\220); STS de 29 de junio de 2002 (RJ 2002\7981). 
Ahora bien, no compartimos con carácter general este posicionamiento jurisprudencial porque entendemos que se opone a la propia configuración legal y jurisprudencial del ejercicio de la acción civil en el proceso penal. Santos Briz expone ${ }^{12}$ : "es doctrina constante de la Sala $1^{a}$ del TS que las sentencias firmes dictadas por los Tribunales de la jurisdicción penal de carácter condenatorio no sólo vinculan a los de orden civil en cuanto a los hechos que se declaran probados, sino que tienen el concepto de definitivas respecto de los problemas que resuelven, sobre los que no se puede volver, y por tanto quedan definitivamente resueltas las responsabilidades civiles derivadas del delito o de la falta, si asi se declara, por lo que la ley autoriza a los perjudicados para justificar la entidad de los perjuicios sufridos dentro del procedimiento penal, si así lo desean, o para reservarse la acción civil dimanante del hecho punible para ejercitarla en el oportuno proceso independiente del criminal, evitando que en éste se haga pronunciamiento sobre la materia S. de 14 de diciembre de 1961 y 20 de marzo de 1975)». En la misma línea, podemos citar también las sentencias de la Sala $1^{a}$ del Tribunal Supremo de 4 de noviembre de 1991 (RJ 1991\7932); STS n 721/1993, de 12 de julio (RJ 1993\6007); STS n ${ }^{\circ}$ 474/2003, de 20 de mayo (RJ 2003\4862).

Estas conclusiones encuentran su fundamento en el reconocimiento jurisprudencial del carácter civil de la responsabilidad civil ex delicto. El Tribunal Supremo así lo ha señalado en algunos de sus pronunciamientos negando el hecho que su regulación en el Código Penal haga perder esta condición. En la sentencia del Alto Tribunal de 27 de mayo de 1992 (RJ 1992\4951), dispone que «en todo caso, sobre la responsabilidad civil "ex delicto", es preciso recordar que la acción civil para reclamar la indemnización pertinente no pierde su naturaleza civil por el hecho de ser ejercitada en un proceso penal [v. S. 25-1$1990(R J 1990 \backslash 504)^{13}$. En la sentencia del Tribunal Supremo $\mathrm{n}^{\circ}$ 936/2006, de 10 de octubre (RJ 2006\7705), se equipara la responsabilidad civil ex delicto con la responsabilidad extracontractual ordinaria prevista en el Código Civil. Al tener el mismo carácter, estamos ante una relación jurídica material privada en la que rige plenamen-

12 SAntos BrIz, Jaime, La responsabilidad civil. Temas actuales. Montecorvo, Madrid, 2007.

13 En la misma línea: STSJ Islas Baleares $n^{\circ}$ 196/2007, de 30 de abril (AS 2007 2097); STSJ Madrid no 24/2004, de 27 de septiembre (JUR 2004\251626); STSJ Comunidad Valenciana ${ }^{\circ}$ 17/2002, de 23 de septiembre (ARP 2002\756). Destacamos también las sentencias del Tribunal Supremo ${ }^{\circ} 1311 / 1997$, de 28 de octubre (RJ 1997\8111); STS no 221/1997, de 20 de febrero (RJ 1997\1564) y nº 1285/1997, de 24 de octubre (RJ 1997 7290). 
te el principio de autonomía de la voluntad, en la que existen derechos subjetivos de los que sus titulares tienen plena disposición. En el ámbito procesal, este aspecto tiene una especial transcendencia, porque operarán los principios de oportunidad y sus derivados, el dispositivo y el de aportación de parte ${ }^{14}$.

El carácter civil de esta institución comportará que el reconocimiento de la responsabilidad civil ex delicto en vía penal impedirá el ejercicio de la misma pretensión en orden civil. Ahora bien, no podemos olvidar que desde la reforma del art. 146.1 de la Ley 30/1992, de 26 de noviembre, de régimen jurídico de las administraciones públicas y procedimiento administrativo común, efectuada por la Ley 4/1999, de 13 de enero, no es posible acudir a la vía civil para la exigencia de responsabilidad extracontractual de forma directa a las autoridades, funcionarios o personal al servicio de las administraciones públicas, ya sean demandados conjuntamente con la administración a la que pertenecen o de forma exclusiva ${ }^{15}$. La antigua redacción del art. 146.1 de la Ley 30/1992, de 26 de noviembre, «la responsabilidad civil y penal del personal al servicio de las Administraciones Públicas se exigirá de acuerdo con lo previsto en la legislación correspondiente» se ha substituido por la siguiente, «la responsabilidad penal del personal al servicio de las Administraciones públicas, así como la responsabilidad civil derivada del delito se exigirá de acuerdo con lo previsto en la legislación correspondiente», de forma que se cierran totalmente las puertas para la exigencia de responsabilidad extracontractual en vía civil ${ }^{16}$. De acuerdo con el art. 145.1 de la Ley 30/1992, de 26 de noviembre, la administración responderá de forma directa de los daños causados por las autoridades y personal a su servicio, sin perjuicio del derecho de repetición que le reconoce el se-

${ }^{14}$ Dispone la sentencia en el fundamento jurídico séptimo:

«1) El proceso civil sólo podrá iniciarse a instancia de parte, con lo que habrá de ejercitarse en él una verdadera pretensión, dependiendo por tanto de la decisión del perjudicado el acudir o no al proceso.

2) El objeto del proceso será determinado por el perjudicado demandante y el órgano judicial habrá de ser congruente en la resolución, sin que pueda conceder más de lo pedido, en aras del respeto a los principios acusatorio o de congruencia (...)

3) Dada la naturaleza plenamente dispositiva de la responsabilidad civil, nada impide que sobre la misma se realicen todos los actos de disposición que se refieran, bien al objeto del proceso, esto es, a la pretensión civil (allanamiento, renuncia, transacción), bien al proceso, lo que en este caso puede llevar, no exactamente al desistimiento en sentido estricto, pero si a la reserva de la acción, para ejercitarla o no en un posterior proceso civil.»

15 Torrent Ribert, Pere-Joan, y otros autores. Introducció al dret local de Catalunya. Cedecs, Barcelona, 2005.

16 STS n ${ }^{\circ}$ 93/2006, de 17 de febrero (RJ 2006\889). 
gundo párrafo de dicho precepto. En un mismo sentido, de conformidad con el art. 2 e) de la Ley 29/1998, de 13 de julio, reguladora de la Jurisdicción Contencioso-Administrativa el orden jurisdiccional contencioso-administrativo conocerá de las cuestiones que se susciten en relación con la responsabilidad patrimonial de las Administraciones públicas, cualquiera que sea la naturaleza de la actividad o el tipo de relación de que derive, no pudiendo ser demandadas aquéllas por este motivo ante los órdenes jurisdiccionales civil o social, aun cuando en la producción del daño concurran con particulares o cuenten con un seguro de responsabilidad ${ }^{17}$.

A pesar que la jurisdicción civil en la actualidad no pueda conocer de las reclamaciones de responsabilidad patrimonial contra las administraciones públicas y el personal a su servicio, entendemos que la doctrina expuesta del agotamiento de la acción civil con su ejercicio en el proceso penal cuando hay sentencia condenatoria es plenamente equiparable en el caso del ejercicio de la acción de responsabilidad patrimonial. Con carácter general, si el ejercicio de la acción civil en el proceso penal agota su ejercicio, debería del mismo modo impedir el ejercicio de la acción de reclamación de responsabilidad patrimonial posterior en vía administrativa sobre los mismos hechos. Esto sería posible mediante la aplicación del régimen jurídico propio de la responsabilidad patrimonial de las administraciones públicas previsto en las leyes administrativas para la determinación de la la responsabilidad civil ex delicto de las administraciones públicas. Si el juez penal sigue los principios civiles a la hora de determinar la responsabilidad civil ex delicto con carácter general, en el caso de enjuiciamiento de la responsabilidad civil ex delicto de los entes públicos, debería seguir también los principios que inspiran la responsabilidad de las administraciones públicas, no en el ámbito civil, sino en el ámbito administrativo puesto que tienen un régimen jurídico propio ajeno al ámbito civil. Y éste es el establecido en la Ley 30/1992, de 26 de noviembre, de régimen jurídico de las administraciones públicas y procedimiento administrativo común ${ }^{18}$.

17 Nueva redacción efectuada por la Ley Orgánica 19/2003, de 23 de diciembre, por la que se puso fin al debate doctrinal y jurisprudencial sobre cuál era la jurisdicción competente para conocer de las pretensiones en materia de responsabilidad patrimonial cuando se demandaba a particulares y/o a aseguradoras conjuntamente con la administración. El art. 9.4 de la Ley Orgánica 6/1985, de 1 de julio, del Poder Judicial, se pronuncia en los mismos términos.

${ }_{18}$ Sin perjuicio, claro está, que deben darse los presupuestos sustantivos y procesales exigidos por las leyes penales en orden a la determinación de la responsabilidad civil ex delicto. 
De forma muy tímida, alguna sentencia penal indirectamente ha apuntado esta posibilidad. La sentencia de la Audiencia Provincial de Ciudad Real n ${ }^{\circ} 21 / 2003$, de 22 de septiembre (JUR 2003 251043) parece que pretenda equiparar o aproximar ambas figuras cuando se refiere al "funcionamiento normal o anormal de los servicios públicos» en sede de responsabilidad civil ex delicto. En la misma línea, la sentencia del Tribunal Superior de Justicia de Madrid n ${ }^{\circ} 10 / 2002$, de 26 de julio (JUR 2002 257095) condena el Estado como responsable civil subsidiario en un supuesto de funcionamiento normal de la Administración de Justicia.

No obstante, cabría contemplar algunas salvedades o excepciones a esta regla general. Serían los casos en que existiendo un pronunciamiento penal previo condenatorio sobre unos determinados hechos con fijación de la correspondiente responsabilidad civil, aparecen daños que no se tuvieron en cuenta en este proceso inicial. En estos supuestos, la sentencia civil sería complementaria a la penal. La sentencia del Tribunal Supremo de 9 de febrero de 1988 (RJ 1988/771) establece en el fundamento jurídico cuarto esta posibilidad: «(...) Es sabida y proclamada por constante jurisprudencia la prevalencia de la sentencia penal condenatoria sobre la civil en aquellos supuestos en los cuales, como en el presente, unos hechos ilícitos, culposos o negligentes, sean, al propio tiempo, constitutivo de delito o falta, en el orden de fijación de los elementos constitutivos del ilícito penal y de sus consecuencias en la responsabilidad civil -Sentencias de esta Sala de 4-XI-1986 (RJ 1986\6206), 2-XI-1987 (RJ 1987 \8129) y 18-XI1987, entre otras-, de tal manera que, dictada una sentencia penal condenatoria, no puede una sentencia civil posterior volver sobre el mismo asunto para suplir sus posible errores o deficiencias. Pero la aplicación de esta doctrina requiere que no se vuelva sobre hechos ya establecidos en la sentencia penal, pero en principio la sentencia civil puede servir de complemento a una penal para supuestos que, en ella, no se tuvieron ni se pudieron tener en cuenta-Sentencias de esta Sala de 27-1-1981 (RJ 1981\41) y 13-V-1985 (RJ 1985\2273)- y fundamentalmente ante la presencia de unos resultados de la conducta delictiva, imprevisibles en el momento en que se dictó la sentencia penal, se admiten la posibilidad de pedir por vía civil, la indemnización de aquellos resultados no previstos -Sentencias de esta Sala de 25-III-1976 (RJ 1976\1428) y 11-XII-1979 (RJ 1979\4360)-, pues sería artificiosa solución, contraria a la naturaleza de las cosas, aquellas que pretenda negar la innegable realidad de un daño sobrevenido como consecuencia de una actuación ilícita que, cuando fue juzgada, presentaba mejores perspectivas dentro de las posibilidades, siempre falibles, de los criterios de 
valoración que, en aquel momento se podían aplicar racionalmente, pero que han sido desbordados por la realidad. En tales casos, ante la imposibilidad de plantear otro proceso penal para reenjuiciar la conducta básica, si se negara la viabilidad de la pretensión de resarcimiento por medio del proceso civil se produciría un incumplimiento de lo dispuesto en el artículo 24.1 de la Constitución Española (RCL $1978 \backslash 2836$ y ApNDL 1975-85, 2875) pues se negaría el derecho a obtener la tutela efectiva de unos derechos y de unos intereses legítimos, supuestos por el genérico derecho a resarcirse de los males sufridos por conductas ajenas. Por estas razones, demostrada documentalmente la nueva situación, los motivos deben ser estimados en cuanto se debe pasar al estudio de la pretensión tendente a fijar la indemnización que corresponde por nuevos hechos sobrevenidos y proceso penal y no previstos en él» ${ }^{19}$.

En el mismo orden de cosas, la sentencia del Tribunal Supremo de 27 de enero de 1981 (RJ 1981 41 ) admite la posibilidad de acudir a la vía civil en el caso que exista condena penal previa con expreso pronunciamiento condenatorio civil que fija la determinación en ejecución de sentencia de los gastos legítimos de curación de lesiones y jornales correspondientes a los días impeditivos y esta cuantificación no se produce, porque "en tanto no se haya efectuado aquella concreta determinación en la referida ejecución de la expresada sentencia penal, el efectuarlo mediante el planteamiento de juicio civil a esa finalidad, porque en tal aspecto la referida ejecutoria penal es un título de crédito, creador de un vínculo obligacional, al que puede darse efectividad en tal marco procedimental civil si a él decidiere acudir el que lo obtuvo a su favor».

Los mismos razonamientos, en aras a garantizar el derecho a la tutela judicial efectiva de las víctimas, pueden aplicarse para permitir el ejercicio de la reclamación de responsabilidad patrimonial, aunque exista sentencia penal previa condenatoria donde se haya fijado la responsabilidad civil, en aquellos casos en que aparezcan nuevas lesiones o distintas secuelas de las fijadas originariamente derivadas de los mismos hechos.

De todas formas, es preciso recordar que esta interpretación se aparta de la jurisprudencia mayoritaria que se postula a favor de la posibilidad de acudir a la vía administrativa y contencioso-administrativa aunque exista previa sentencia penal condenatoria sobre los

19 En un mismo sentido, citamos la STS de 15 de marzo de 1991 (RJ 1991/2259) o el auto $\mathrm{n}^{\circ}$ 150/2006, de 12 de septiembre, de la AP de Madrid (JUR 2007 31471). 
mismos hechos, absolviendo o condenando a la administración en la correspondiente pieza separada de responsabilidad civil ${ }^{20}$.

\section{III.2. Resolución penal previa absolutoria}

En el caso que el procedimiento penal finalice sin condena, la administración y los juzgados y tribunales del orden jurisdiccional contencioso-administrativo pueden conocer del asunto a posteriori si bien quedarán vinculados por la declaración de hechos probados efectuada por la sentencia penal firme. Para ser más precisos, quedarán vinculados a los hechos que han motivado al tribunal a declarar el sobreseimiento o a dictar sentencia absolutoria. En consecuencia, es poco probable que se obtenga en el procedimiento administrativo o contencioso-administrativo un pronunciamiento favorable a las pretensiones del reclamante al existir pronunciamiento penal previo absolutorio debido a esta vinculación al relato fáctico de la sentencia.

No obstante, y en atención al distinto fundamento de la responsabilidad patrimonial y la responsabilidad civil ex delicto que predica la jurisprudencia, cabría la posibilidad de obtener una decisión favorable en vía administrativa o contencioso-administrativa a pesar de existir sentencia penal absolutoria. Al no haber pronunciamiento del juez penal sobre la responsabilidad civil derivada del delito, no se ha podido agotar el ejercicio de la acción de responsabilidad patrimonial $^{21}$. La ausencia de dolo o culpa relevantes penalmente, no sería obstáculo para decretar la responsabilidad en vía administrativa porque ésta tiene un carácter objetivo. Pensemos por ejemplo en una caída de una persona en la vía pública que le ocasiona daños considerables como consecuencia de unas obras municipales que se estaban ejecutando. Viene siendo habitual que los tribunales penales acuerden en estas situaciones desde un inicio el archivo de las actuaciones (siempre que no aprecien que los hechos sean susceptibles de responsabilidad penal). Pues bien, en estos casos, las víctimas podrían plantear la correspondiente acción administrativa de reclamación

20 SAN de 18 de marzo de 2005 (RJCA 2005\655); SAN de 20 de mayo de 2005 (JUR 2005\249473); SAN de 1 de marzo de 2001 (JUR 2001/104980); STS de 20 de octubre de 1997 (RJ 1997\7254).

${ }_{21}$ Cabría contemplar alguna excepción a esta regla general, como podrían ser los casos en que a pesar de no existir responsabilidad criminal por la concurrencia de determinadas circunstancias eximentes pudiera haber responsabilidad civil (art. 118 del $\mathrm{CP})$. 
de responsabilidad patrimonial. De lo contrario, se dejaría a los agraviados en una situación de clara indefensión al no poder resarcirse de los daños sufridos en su esfera personal o patrimonial.

El propio art. 116 de la Ley de Enjuiciamiento Criminal establece que la extinción de la acción penal no lleva consigo la de la civil, a no ser que la extinción proceda de haberse declarado por sentencia firme que no existió el hecho de que la civil hubiese podido nacer. En los demás casos, la persona a quien corresponda la acción civil podrá ejercitarla ante la jurisdicción y por la vía de lo civil que proceda, contra quien estuviere obligado a la restitución de la cosa, reparación del daño o indemnización del perjucicio sufrido. La sentencia de la Audiencia Provincial de Madrid $\mathrm{n}^{\circ}$ 164/2006, de 20 de abril (JUR 2006 296922), destaca que «Siendo la sentencia absolutoria del acusado en el ámbito penal, carecen así mismo de virtualidad los motivos del recurso encaminados a pretender la condena civil del acusado y de la entidad aseguradora como responsable civil directa, por cuanto la acción civil exdelicto tiene carácter subsidiario y dependiente de la acción penal en todo procedimiento criminal, y el de faltas lo es, de tal suerte que únicamente cabe realizar pronunciamiento sobre la misma cuando haya existido un pronunciamiento condenatorio contra el acusado en el ámbito penal. Así se constata plenamente del artículo 109.1 Código Penal al establecer que la ejecución de un hecho descrito por la ley como delito o falta obliga a reparar, en los términos previstos en las leyes, los daños y perjuicios por él causados. Al igual que del artículo 116.1 del mismo cuerpo legal al establecer que toda persona criminalmente responsable de un delito o falta lo es también civilmente si del hecho se derivaren daños o perjuicios. Es por ello por lo que si no ha existido el delito o falta que inicialmente se imputa al acusado, como acaece en el supuesto analizado en el que la sentencia es absolutoria en su contenido penal, el tribunal de lo criminal pierde toda competencia para el conocimiento de la acción civil que queda imprejuzgada y puede ser ejercitada por su titular ante los órganos civiles competentes, tal y como contempla el artículo 116 de la LE Criminal "La extinción de la acción penal no lleva consigo la de la civil, a no ser que la extinción proceda de haberse declarado por sentencia firme que no existió el hecho de que la civil hubiese podido nacer. En los demás casos, la persona a quien corresponda la acción civil podrá ejercitarla, ante la jurisdicción y por la vía de lo civil que proceda, contra quien estuviere obligado a la restitución de la cosa, reparación del daño o indemnización del perjuicio sufrido.»

La sentencia del Tribunal Supremo ${ }^{\circ} 1061 / 2005$, de 30 de septiembre (RJ 2005\7063) dispone en la misma línea que: «En efecto la 
sentencia de instancia, fundamento derecho cuarto, se remite al art. 116 CP. (RCL 1995, 3170 y RCL 1996, 777) para declarar que no procede determinar responsabilidades civiles. Pronunciamiento correcto por cuanto la responsabilidad civil derivada del delito viene subordinada a la responsabilidad penal que surge del mismo, de modo que el conocimiento de la acción civil dentro del proceso penal tiene carácter eventual por estar condicionada por la existencia de responsabilidad penal. La sentencia absolutoria por no ser los hechos constitutivos de un delito de estafa impide resolver la reclamación civil en el proceso penal y hace necesario plantear la reclamación civil ante los Tribunales ordinarios de esa jurisdicción, pues aquella responsabilidad viene de modo indeclinable subordinada a la criminal, que surge de todo delito.

En consecuencia, es claro que si se absuelve del delito de que dichas indemnizaciones iban a prevenir, no puede declararse esta responsabilidad civil, consecuencia de la criminal y que no puede exigirse sin la previa declaración de la existencia del hecho punible del que dimana».

Los mismos argumentos son de aplicación en el ejercicio de la acción de reclamación de responsabilidad patrimonial. La jurisprudencia de los tribunales del orden jurisdiccional contencioso-administrativo se pronuncia también en esta línea ${ }^{22}$. Recordemos que en la actualidad no es posible el ejercicio de acción civil directa del perjudicado contra el funcionario después de la reforma operada por la Ley 4/1999, de 13 de enero, del art. 146.1 de la Ley 30/1992, de 26 de noviembre, de régimen jurídico de las administraciones públicas y procedimiento administrativo común.

\section{III.3. Finalización previa del procedimiento administrativo o contencioso-administrativo estimando o desestimado la reclamación de responsabilidad patrimonial}

En el caso que previamente haya resolución administrativa o sentencia dictada por los tribunales de lo contencioso-administrativo estimatoria o desestimatoria de la reclamación de responsabilidad patrimonial lógicamente no obstaculizaría al posterior ejercicio de la acción penal sobre los mismos hechos. Hay que señalar, como salvedad,

22 STS de 12 de junio de 2008 (RJ 2008\6375); STS de 15 de julio de 1991 (RJ 1991\6167); STSJ Castilla y León no 596/2009, de 3 de marzo (JUR 2009\209073); STSJ Cataluña ${ }^{\circ} 358 / 2006$, de 12 de abril (JUR 2006\262764) -aunque en este supuesto la causa del archivo de las actuaciones penales sea la prescripción de la falta imputada-; STSJ Extremadura $n^{\circ}$ 984/2001, de 24 de mayo (JUR 2001\191755); STSJ Andalucía n ${ }^{\circ}$ 1400/1998, de 19 de octubre (RJCA 1998\4024). 
que si bien se podría ejercer la correspondiente acción penal, no se podría ejercer la acción civil derivada del delito en el proceso penal porque que ésta se ha agotado con la resolución de la reclamación de responsabilidad patrimonial por la administración, revisable en vía jurisdiccional contencioso-administrativa. Únicamente, en el caso en que aparezcan nuevas lesiones o secuelas derivadas de los mismos hechos que no pudieron ser valoradas en el procedimento administrativo o contencioso-administrativo inicial sería posible el pronunciamiento en vía penal. De todas formas, estos supuestos son escasos a la práctica, porque aún partiendo de la presunta autonomía entre ambas instituciones, lo normal es que se ejercite en primer término la acción penal por tener ésta carácter preferente.

\section{CONCLUSIONES}

A modo de síntesis, podemos establecer las siguientes consideraciones en referencia a las relaciones entre ambas modalidades de responsabilidad:

1) Hay un reconocimiento legal y jurisprudencial a favor del ejercicio simultáneo de la acción civil derivada del delito y de la acción de reclamación de responsabilidad patrimonial en vía administrativa. Al mismo tiempo, la jurisprudencia admite el ejercicio sucesivo de ambas acciones.

2) La existencia de una sentencia penal condenatoria con el reconocimiento de la responsabilidad civil subsidiaria de las administraciones públicas derivada del delito debería impedir una eventual posterior reclamación de responsabilidad patrimonial en relación a los mismos hechos. Excepcionalmente, se podría admitir en aquellos casos en que aparecieran nuevos daños sobrevenidos o que no pudieron tenerse en cuenta en el proceso inicial.

Este criterio se opone a la jurisprudencia mayoritaria que se postula a favor de la posibilidad de ejercer la acción administrativa de reclamación de responsabilidad patrimonial a pesar de la existencia de una resolución penal previa condenatoria con expreso reconocimiento de la responsabilidad civil de la administración.

Por contra, una sentencia penal previa absolutoria no impediría el planteamiento de una ulterior reclamación de responsabilidad patrimonial sobre los mismos hechos porque no se ha podido agotar su ejercicio en el proceso penal. 
3) A la inversa, los mismos argumentos son aplicables en el caso de resolución administrativa o sentencia contencioso-administrativa previa.

4) El régimen jurídico de la responsabilidad patrimonial de las administraciones públicas previsto en la Ley 30/1992, de 26 de noviembre, de régimen jurídico de las administraciones públicas y procedimiento administrativo común podría ser de aplicación por parte del juez penal en orden a la determinación de la responsabilidad civil ex delicto de las administraciones públicas. Todo esto, sin perjuicio de los presupuestos sustantivos y procesales establecidos en las leyes penales.

La naturaleza civil de la responsabilidad civil derivada del delito y la doctrina legal fijada por la sala primera del Tribunal Supremo referente al agotamiento de la acción civil cuando se ejercita en el proceso penal apoyarían esta tesis. 